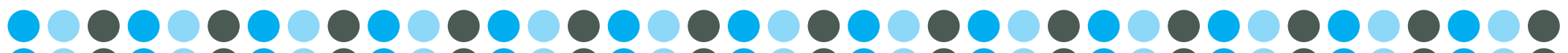

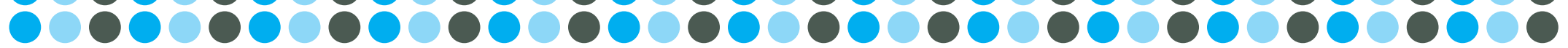

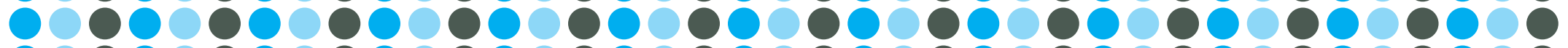

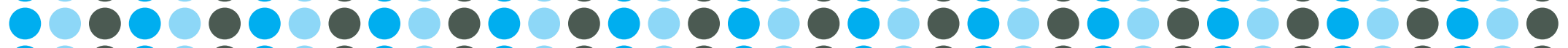

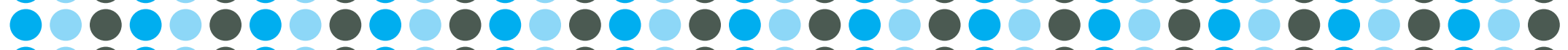

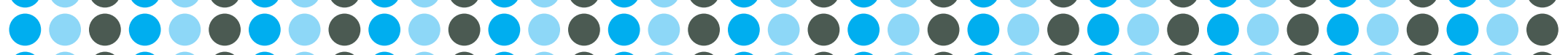

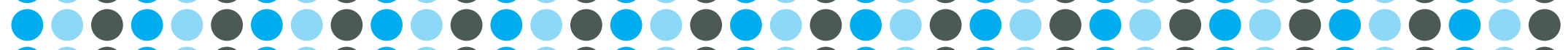

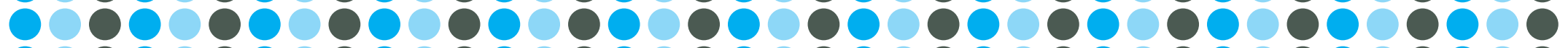

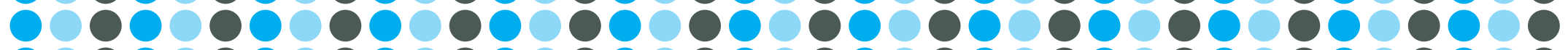

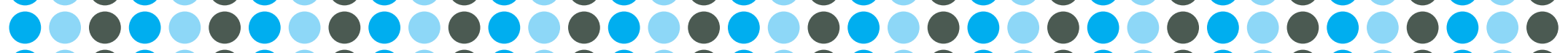

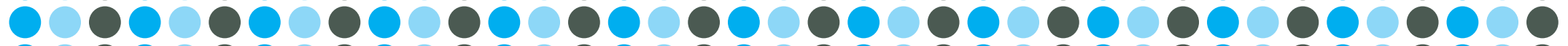

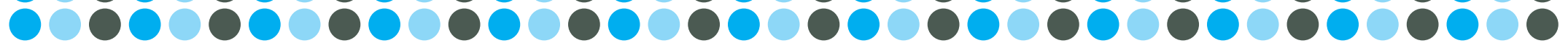

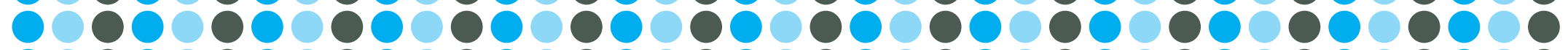

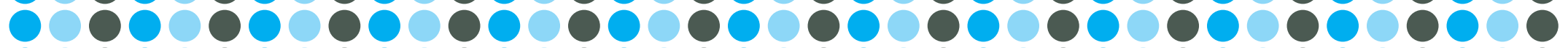

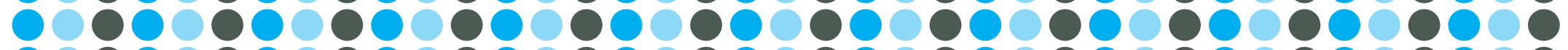

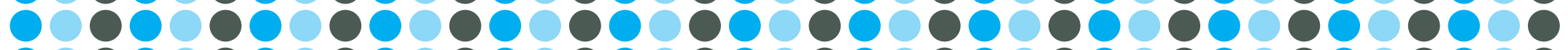

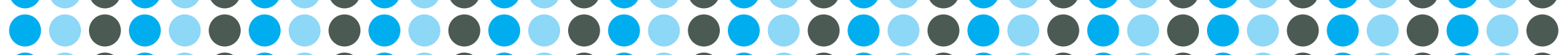

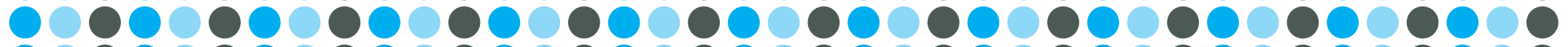

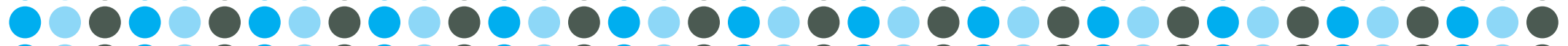

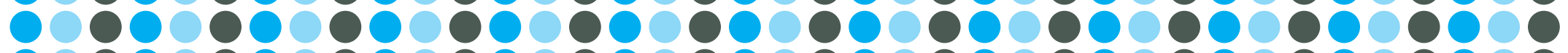

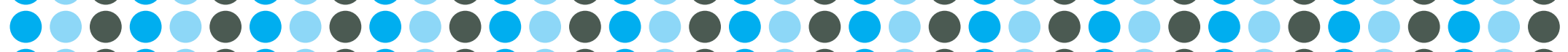

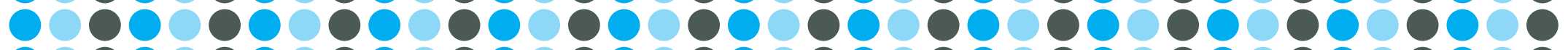

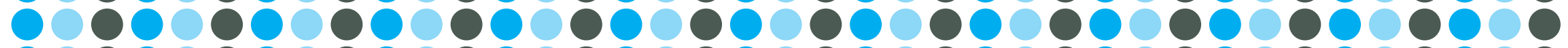

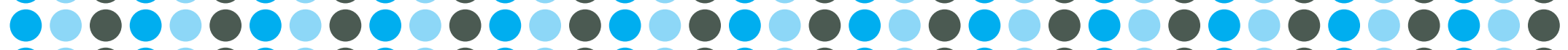

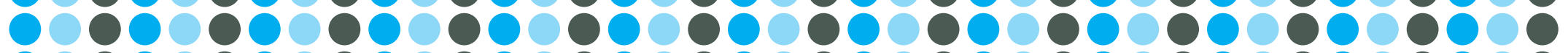

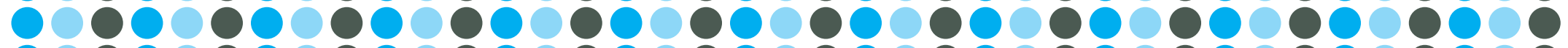

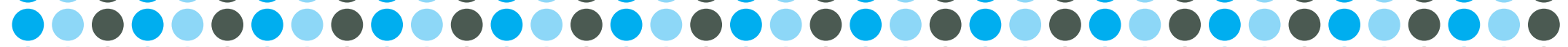

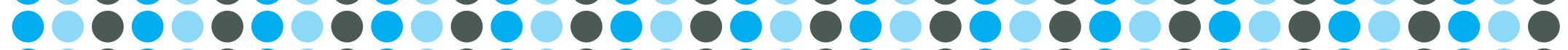

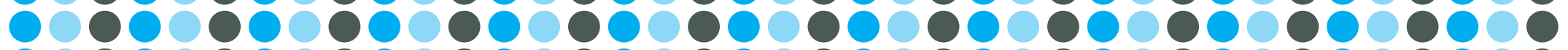

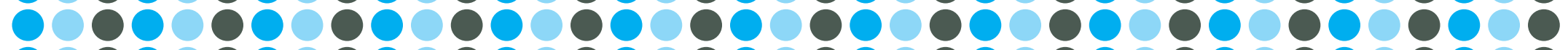

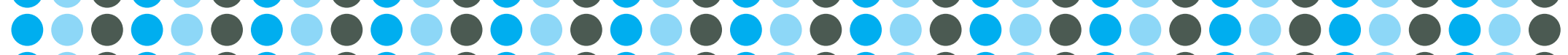

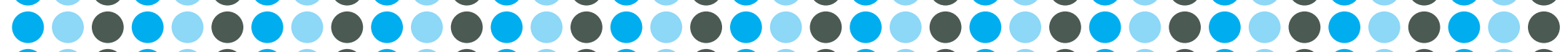

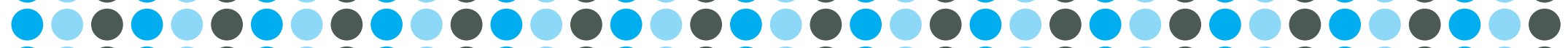

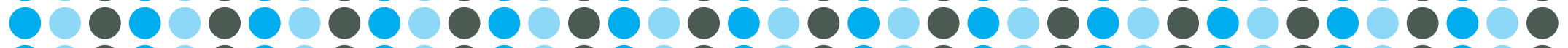

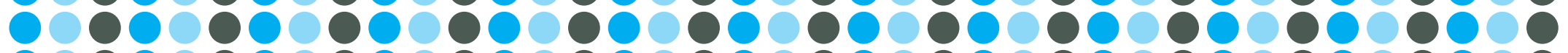

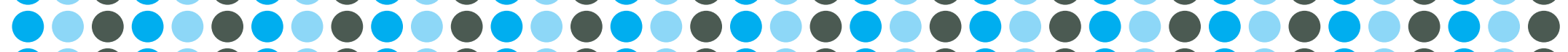

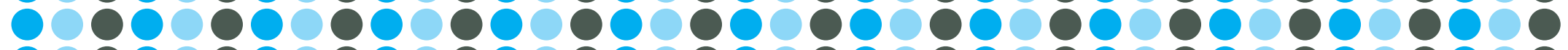

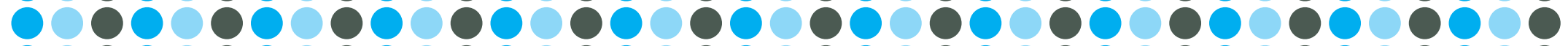

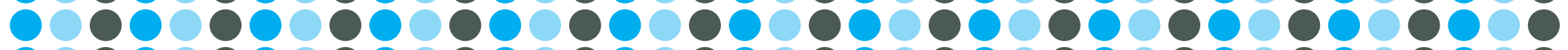

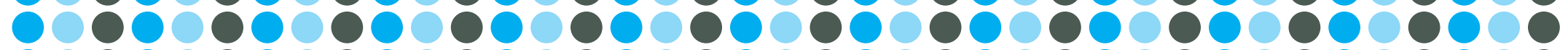

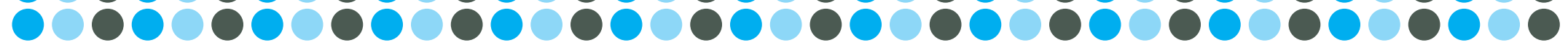




\section{THE DIRT AND THE BEES The Epidemiology of Neonicotinoids}

NEONICOTINOIDS, SUCH AS THIAMETHOXAM (TMX) AND ITS METABOLITE CLOTHIANIDIN (CLO), ARE WIDELY USED INSECTICIDES COMMONLY COATED ON PLANTING SEEDS. DUE TO THEIR CONTAMINATION OF WATERWAYS, THEIR ACCUMULATION IN AQUATIC ORGANISMS IS OFTEN LETHAL AND POSSIBLY CONTRIBUTES TO THE DECLINE OF HONEY BEES. IN ORDER TO UNDERSTAND THE DISTRIBUTION OF TMX AND CLO IN AN AGRICULTURAL-URBAN-MIXED IMPACTED STREAM, THEIR LEVELS IN SEDIMENTS FROM SEVEN LOCATIONS ALONG STROUBLES CREEK, BLACKSBURG WERE INVESTIGATED. THE SEDIMENT SAMPLES WERE EXTRACTED USING LIQUID/SOLID EXTRACTION, CLEANED UP USING PSA, AND ANALYZED ON A LIQUID CHROMATOGRAPHY-TANDEM MASS SPECTROMETER (UPLC/MS/MS). THE FOLLOWING STUDY SUGGESTS THE ABILITY OF INSECTICIDE TO TRAVEL THROUGH THE SOIL TO THE CREEK, SHOWS LOWER LEVELS OF CLO THAN TMX, AND REVEALS THE NECESSITY OF FURTHER RESEARCH IN REGARDS TO CLO CONCENTRATION. OVERALL, THIS STUDY RE-AFFIRMS THAT TMX CAN TRAVEL INTO AN ADJACENT AQUATIC SYSTEM, WHICH HONEY BEES USE FOR THEIR WATER FORAGING NEEDS. 


\section{INTRODUCTION}

Given the widespread use of insecticides, their correlation with honey bee decline warrants further investigation. Neonicotinoids are highly soluble insecticides applied to soil and seeds to target anthropods on crops. First marketed in 1998, TMX, a second generation neonicotinoid, is an ingredient in the pesticides Platinum, Actara, Centric, Cruiser, Flagship, and Helix produced by Syngenta. ${ }^{\mathrm{I}}$ CLO, a metabolite of TMX, is also used as an insecticide. Though neonicotinoids are mainly used for agricultural purposes, other uses include structural pest control, landscaping, and pet treatment for fleas and ticks. ${ }^{2}$ They are widely used to to the point where all corn seeds and a third of soybean seeds in the U.S. are treated with neonicotinoids. ${ }^{3}$

Notwithstanding its extensive usage, several concerns about neonicotinoids' environmental impacts have arisen. Most notably, these pesticides are thought to be a cause in the sharp decline of honey bees in recent years. Due to its use on crops, the European Food Safety Authority determined that the risk of CLO dust drift from drilling sugar beet seeds was enough to indicate a low acute risk for honey bees. Furthermore, the application rate of CLO on sugar beets was determined to be significantly less than the rate of use on maize and other crops. ${ }^{4}$ Although there is no direct evidence that neonicotinoids in surface water are harmful to honey bees, concentrations of o.I4 to I8 ppb are sublethal to non-target aquatic anthropods and have been found in $80 \%$ of surface waters across nine countries. ${ }^{5}$

To understand the occurrence of neonicotinoids in wetlands adjacent to fields harvesting various types of crops, a study in the Prairie region of Canada analyzed both water samples and sediment samples for neonicotinoids. The water samples, which were central in the wetlands and distant from vegetation and surrounding plants, indicated that neonicotinoids were present in $62 \%$ of wetlands' water after seeding occurred in the fields. Where detected, there was $2.3 \mathrm{ng} / \mathrm{L}$ to I2I ng/L of TMX and $0.8 \mathrm{ng} / \mathrm{L}$ to I42 ng/L of CLO. Simultaneously, only $6 \%$ of the wetlands had sediment that contained neonicotinoids, with $20 \mu \mathrm{g} / \mathrm{kg}$ TMX and $2.8 \mu \mathrm{g} / \mathrm{kg}$ CLO to $4.4 \mu \mathrm{g} / \mathrm{kg}$ CLO where detected. ${ }^{6}$ The frequency of neonicotinoids in water is higher than that in sediment; thus, it is assumed that they are more likely to be in a body of water than in the sediment at the bottom. Despite this, the concentration of the compounds is significantly higher in sediment than the concentrations in the water samples, suggesting that neonicotinoids accumulate more readily in sediment than they do in water. Both the solubility of neonicotinoids in water and the high fluidity of water itself cause neonicotinoids to move more throughout the liquid. The neonicotinoids adsorb the sediment at the bottom of surface streams, the extent of which varies based on the composition of that particular sediment. Through adsorption, the insecticides have a greater ability to accumulate in the sediment at those places which warrant it.

Due to the high usage of these pesticides, the length of time they survive in the soil before degradation is important in understanding the possibility of accumulation in both soil and water sources. In a lab setting of normal field conditions, the half-life of TMX in lab soil is $34-75$ days. However, half-life could triple with unfavorable conditions, such as dry soil with less microbial activity.7 TMX tends to adsorb more into the soil with time,causing it to bind and become immobileI. TMX has shown to degrade in water with a half-life of $24-44$ days in anaerobic conditions and 8-16 days in aerobic conditions, ${ }^{8}$ while CLO has shown a degradation of 148 to II55 days in soil and 27 days in anaerobic aquatic conditions. 9

Although TMX is shown to become less mobile in soil with time, some of the compound is still able to move away from the intended area and into surrounding water sources before the applied TMX becomes completely adsorbed. This is possible because TMX has a high water solubility of 4.I g/L, making it highly mobile in water. ${ }^{10}$ According to a study in Ontario, the main reasons for this transfer are carry over soil residues from previous applications, spilled seed, planted seed, and contamination of excess planter dust on the soil surface. ${ }^{\text {IO }}$ Puddles of standing water were analyzed within and outside maize fields during the planting season. The concentration of neonicotinoid residue was found to be consistent outside of the fields, yet within the fields, the concentration increased during the first five weeks after planting and after a rain event. ${ }^{\text {Io }}$ Another study on potato fields showed how accumulation of leachate occurs due to irrigation of water runoff from the fields and

\section{"Most notably, these pesticides are thought to be a cause of the sharp decline of honey bees in recent years."}


rainfall. The killing of vines during potato production causes more leachate to mobilize in the soil. ${ }^{\text {II }}$ Collectively, substantial evidence suggests that neonicotinoids are capable of eliciting unforeseen consequences in their transport and accumulation.

A study in the Midwestern US found TMX in $47 \%$ of 79 stream flow water samples collected at nine sites, and CLO was found in $75 \%$ of the samples. ${ }^{8}$ The TMX and CLO concentration ranged from $5.6 \mathrm{ng} / \mathrm{L}$ to $\mathrm{I} 85 \mathrm{ng} / \mathrm{L}$ and $6.3 \mathrm{ng} / \mathrm{L}$ to $257 \mathrm{ng} / \mathrm{L}$, respectively. Since TMX degrades rapidly under aerobic, aquatic conditions, it not considered a high threat to non-target species, such as vertebrates. However, TMX has shown to metabolize readily to CLO on leaves and insect larvae. It was even shown after a soil drench in TMX that the concentration of CLO on the leaves was twice that of the TMX. ${ }^{\mathrm{I2}}$ CLO has been shown to be more antagonistic to non-target species than TMX and its degradation is not as rapid. Thus, it is imperative that TMX/CLO transport efficiency is characterized for a better understanding of their potentially deleterious effects.

The occurrence of TMX and CLO residues was investigated across seven locations of Stroubles Creek in Blacksburg, VA. As suggested through previous studies of the solubility and mobilization of these compounds, there is the possibility that they are detectable in the sediment of Stroubles Creek at locations where it receives runoff and leachate from an adjacent cornfield. In addition, the aerobic transformation rates of TMX and CLO in both sediment and soil were investigated.

\section{MATERIALS AND RESEARCH METHODS}

\section{Sediment Collection}

Sediment submersed in the creek was collected from seven locations along Stroubles Creek (Fig. I). The sediment was then separated from water in a centrifuge in vials containing $40 \mathrm{~mL}$ of sediment each, at the following parameters: temperature $8^{\circ} \mathrm{C}, 4000 \mathrm{rpm}$, and ro minutes. The water was taken out of the vials and the sediment was then freeze dried overnight. The freeze dried sediment was combined with all the sediment from its corresponding location, which was about roo g total sediment. Two grams of sediment sieved through a $2 \mathrm{~mm}$ sieve were used for each sample during the extraction, cleanup, and analysis process. Rocks and other debris were removed in order to detect a more accurate representation of the concentration of neonicotinoids in the sediment.

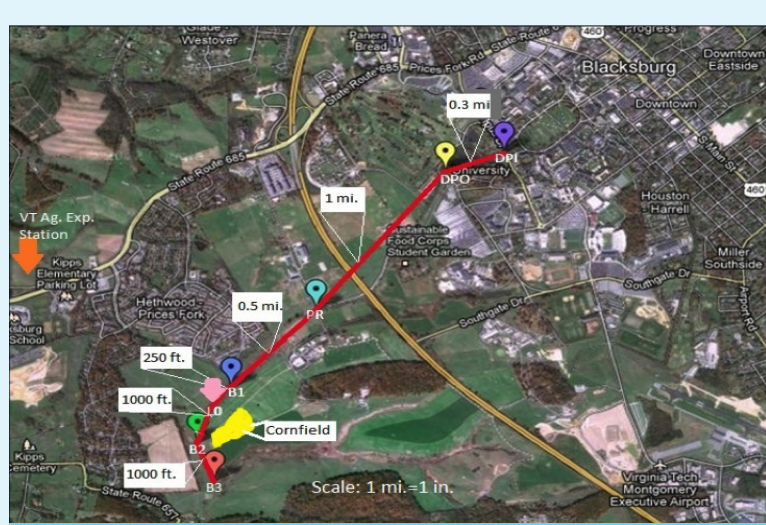

0

FIGURE 1. SAMPLE LOCATION MAP ADDRESS OF VT. AG. EXP. STATION: 3192-3262 PRICES FORK RD, BLACKSBURG, VA 24060

1) VT. AG. EXP. STATION (ORANGE ARROW)

2) DUCK POND IN (DPI, PURPLE PINPOINT)

3) DUCK POND OUT (DPO, YELLOW PINPOINT)

4) PLANTATION ROAD (PR, TEAL PINPOINT)

5) BRIDGE 1 (BT, BLUE PINPOINT)

6) LOCATION O (LO, PINK ARROW)

7) BRIDGE 2 (B2, GREEN PINPOINT)

8) BRIDGE 3 (B3, RED PINPOINT)

\section{Neonicotinoids}

Thiamethoxam (TMX), purchased through Sigma Aldrich and manufactured by FLUKAR, has a purity of $99.6 \%$. A white powder with a molecular mass of 29I.7I g/mol, TMX in acetonitrile stock solution of II. $52 \mathrm{mg} / \mathrm{mL}$ was prepared for use. Clothianidin (CLO), purchased through Sigma Aldrich and manufactured by Chem Service, has a purity of $99.5 \%$. A white powder with a molecular mass of $249.68 \mathrm{~g} / \mathrm{mol}$, and a CLO stock solution of $10.49 \mathrm{mg} / \mathrm{mL}$ were prepared. Stock solutions were prepared by adding $5.76 \mathrm{~g}$ TMX or $5.25 \mathrm{~g}$ CLO to $500 \mathrm{~mL}$ of acetonitrile. Then it was serially diluted IoX to prepare usable concentrations of the compounds, the lowest concentrations of TMX and CLO prepared were I.I52 ppb and I.049 ppb, respectively. Both the TMX and CLO stock solutions were used to prepare standards for use on the LC-MS/MS.

\section{Sediment Incubation Study}

Moist sediment that had been submersed in the creek was collected from Lo of Stroubles Creek (Figure I), separated from its water content, and then frozen for future use for the sediment incubation study to investigate TMX and CLO transformation . 
Using nine wide mouth mason jars with I inch deep of sediment each, three treatments were set up in triplicate to determine the degradation of TMX and CLO in sediment in natural conditions. The three sediment treatments consisted of blank sediment, a concentration of $57.6 \mathrm{ng}$ TMX per gram of sediment and water, and a concentration of $52.5 \mathrm{ng}$ CLO per gram of sediment and water. The jars were kept at $23^{\circ} \mathrm{C}$ and covered tightly with lids to keep conditions consistent. TMX or Clothianidin was added to the sediments, then stirred to thoroughly incorporate the compound in each jar. The sediment was covered in 2 inches of water from the same location where the sediment was collected.

Sampling occurred on days 0 , 3, and Io. A micro spoon was used to collect about I2 $\mathrm{g}$ of soaked sediment from each jar. The samples from each jar went into a test tube to be freeze-dried overnight and I g each was to be extracted for the target analytes at a later date.

\section{Soil Incubation Study}

The soil used for the degradation study was obtained from the Virginia Agricultural Experiment Station (Figure I). No pesticides were used on this soil before, making this soil free of neonicotinoid concentrations. The soil was air dried, sieved through a $2 \mathrm{~mm}$ sieve, and then ground for the incubation study for TMX transformation.

A water holding capacity test was performed on the soil in order to determine the soil moisture content at its 70\% water holding capacity, the water content that would be kept constant throughout the study. To determine the soil water holding capacity, in duplicate , Io० g of air-dried soil was put into a disposable cup with I2 small holes at the bottom. Enough water was then added to fully submerge the soil, and was allowed to drain out for 2 days in order to reach $100 \%$ water holding capacity. Based on weight differences of the cup, it was possible to calculate the amount of water needed to keep the jars at $70 \%$ water holding capacity.

Across six wide mouth mason jars with Ioo g soil each, two treatments were set up in triplicate to determine the degradation of TMX in soil at field conditions. The two soil treatments consisted of blank soil and TMX concentration of $2.3 \mu \mathrm{g}$ per gram air dried soil. The soils were spiked with TMX at the target levels, and then stirred thoroughly to incorporate the TMX with the rest of the soil in each jar. The appropriate amount of deionized water was added to each jar in order to reach a water content at its $70 \%$ water holding capacity. This water content was maintained during the entire incubation time by periodically weighing each jar and adding water accordingly. The jars were kept at $23^{\circ} \mathrm{C}$ and covered with Parafilm to keep aerobic conditions. ${ }^{13}$

Sampling occurred on days o, 3, 7, and 28. A micro spoon was used to collect about I g of moist soil from 3 different places in each jar and composited. The composite samples from each jar went into a test tube to be freeze-dried overnight and I g each was to be extracted for the target analytes at a later date.

TMX and CLO extraction, cleanup, and analysis for sediment and soil samples

Freeze-dried and sieved sediment/soil were measured out using an analytical balance to $2 \mathrm{~g}$ (for sediment detection) or Ig (for incubation studies) and put into $35 \mathrm{~mL}$ roundbottom vials. A vial containing no sediment/soil was also put through the clean-up procedure for comparison. Samples containing a specific amount of added TMX or CLO were spiked at this time (usually Ioo $\mu \mathrm{L}$ of Io० ppb compound). Ten milliliters of acetonitrile was added to each of the vials, which were covered with foil and lids. The samples were vortexed for io seconds each on 6.5 speed. To each vial, $2 \mathrm{~g} \mathrm{MgSO}_{4}$ (anhydrous) and $0.5 \mathrm{~g} \mathrm{NaCl}$ per gram of sediment/soil were added. The samples were vortex mixed for 2 minutes on 6-7 speed then centrifuged in swinging-bucket adapters at these parameters (used for the entire duration of the extraction): $3500 \mathrm{rpm}, 23^{\circ} \mathrm{C}, 6 /$ max accel/decel, and ro minutes. The supernatant from these vials was transferred to another set of $35 \mathrm{~mL}$ roundbottom vials containing $0.5 \mathrm{~g} \mathrm{MgSO}_{4}$ (anhydrous) and o.I PSA sorbent per gram of sediment/soil that had been in the other sample vial. Five milliliters of acetonitrile was added to the sediment/soil vials, which were then vortexed for I. 5 minutes on 7-8 speed and centrifuged. The supernatant from these vials was transferred to the supernatant vials. These vials were then vortexed for 2 minutes on 6 speed and centrifuged. Ten milliliters of the supernatant was transferred using a Io $\mathrm{mL}$ pipet to $25 \mathrm{~mL}$ test tubes to be dried down in the RapidVap at these general parameters: Round I) 60 minutes, I30 mbar, $60 \%$ spin, $35^{\circ} \mathrm{C}$; Round 2) 20 minutes, I40 mbar, $60 \%$ spin, $40^{\circ} \mathrm{C}$. The dried down samples were then redissolved in I $\mathrm{mL}$ of 9:I $\mathrm{H}_{2} \mathrm{O} / \mathrm{MeOH}$ with $5 \mathrm{mM} \mathrm{NH} 4$ Ac. Each final extract was diluted appropriately to fit the upper and lower standard range. Then, using a I $\mathrm{mL}$ syringe, the samples were fil- 
tered through a $0.2 \mu \mathrm{m}$ PTFE filter into a $2 \mathrm{~mL}$ HPLC vial for the UPLC/MS/MS analysis.

The Agilent 6490 Triple Quad LC/MS with the ZORBAX Extend C-I8 analytical guard column $4.6 x i 2.5 \mathrm{~mm}, 5$ micron was used to conduct all relevant experiments. The temperature of the column was maintained at $40^{\circ} \mathrm{C}$. The mobile phase used was (A) $5 \mathrm{mM} \mathrm{NH}_{4} \mathrm{Ac}$ in water and (B) $5 \mathrm{mM} \mathrm{NH} 4 \mathrm{Ac}$ in methanol. The following gradient of mobile phase was used: increase 10\% to $95 \%$ (B) from o to 5 mins., held at $95 \%$ (B) for 2 mins., and then decrease to IO\% (B) for I min. The flow rate used was $0.5 \mathrm{~mL} / \mathrm{min}$, with post time of 3 mins., and injection volume of $5.00 \mu \mathrm{L}$.

\section{RESULTS AND DISCUSSION}

\section{Calibration of UPLC/MS/MS for TMX and CLO detection}

All samples were analyzed on a triple quadruple ultra performance liquid chromatography-tandem mass spectrometer (UPLC/MS/MS). As shown in Figures 2 and 3 , the retention times of TMX and CLO in samples were 3.I5 min. and $3.65 \mathrm{~min}$., respectively, and the ratios between the quantifier and qualifier daughter ions of TMX and CLO in samples were around 40 and Ioo, respectively.

Levels of TMX and CLO in the sediment from Stroubles Creek The highest mean concentration of TMX was $0.788 \mathrm{ppb}$ (Figure 4), found in the sediment samples collected from Stroubles Creek at the second bridge (designated as B2). Sediment samples from all other locations along Stroubles

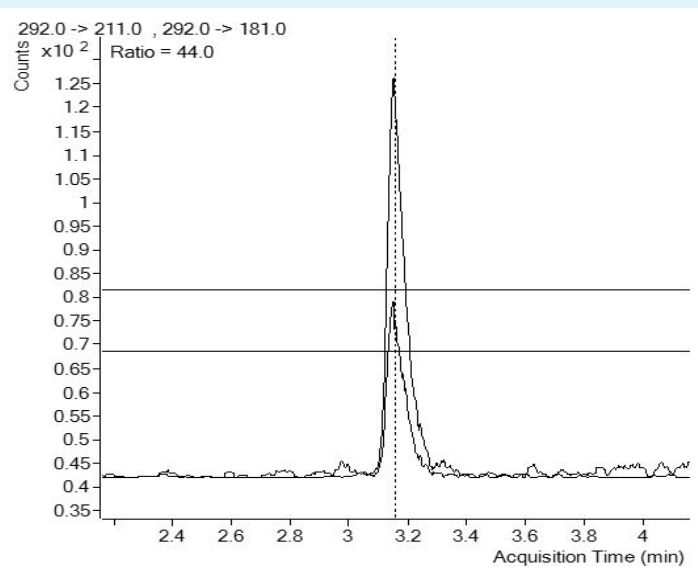

FIGURE 2. CHROMATOGRAM OF TMX STANDARD (0.58 PPB) SHOWING PEAK RETENTION TIME AND RATIO OF QUANTIFIER AND QUALIFIER DAUGHTER IONS
Creek had concentrations that were at most o.I6 ppb (Figure 4). The concentrations in those sediment samples were either lower or very close to the detection limit of o.I $\mathrm{ppb}$. The sediment samples had concentrations of CLO that were all below the detection limit of o.I ppb.

The concentration of TMX in Stroubles Creek was found to be the highest at $\mathrm{B} 2$, the location directly below the cornfield (Figure I), leading to the conclusion that TMX may mobilize readily from the soil in the cornfield to the sediment in the creek. Additionally, the presence of the cornfield itself influences the accumulation of TMX found in Stroubles Creek at that location. CLO is present in various locations along Stroubles Creek, though it is unclear what specific events along the stream would cause an accumulation of the compound. The concentrations of CLO in Stroubles creek do not correlate to any particular contaminator in the way that TMX concentrations reflect the location of the cornfield.

\section{TMX and CLO Transformation Rate in Sediment}

The half-life of TMX in sediment in this study was 8 days and the half-life of CLO in the sediment used in this study was 9 days. Over the course of Io days, no concentrations of CLO were detected in the samples where TMX was transforming. It is important to note that the CLO concentration for Day 3 was found to be higher than the concentration of Day o. This may be due to uneven distribution of the compound in the jars, either just within the sediment or between the water and sediment portions. The afore-

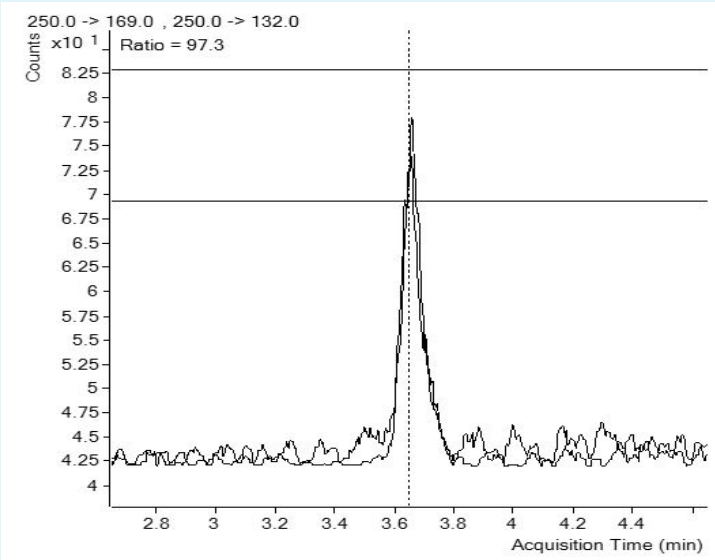

FIGURE 3. CHROMATOGRAM OF CLO STANDARD (0.53 PPB) SHOWING PEAK RETENTION TIME AND RATIO OF QUANTIFIER AND QUALIFIER DAUGHTER IONS 


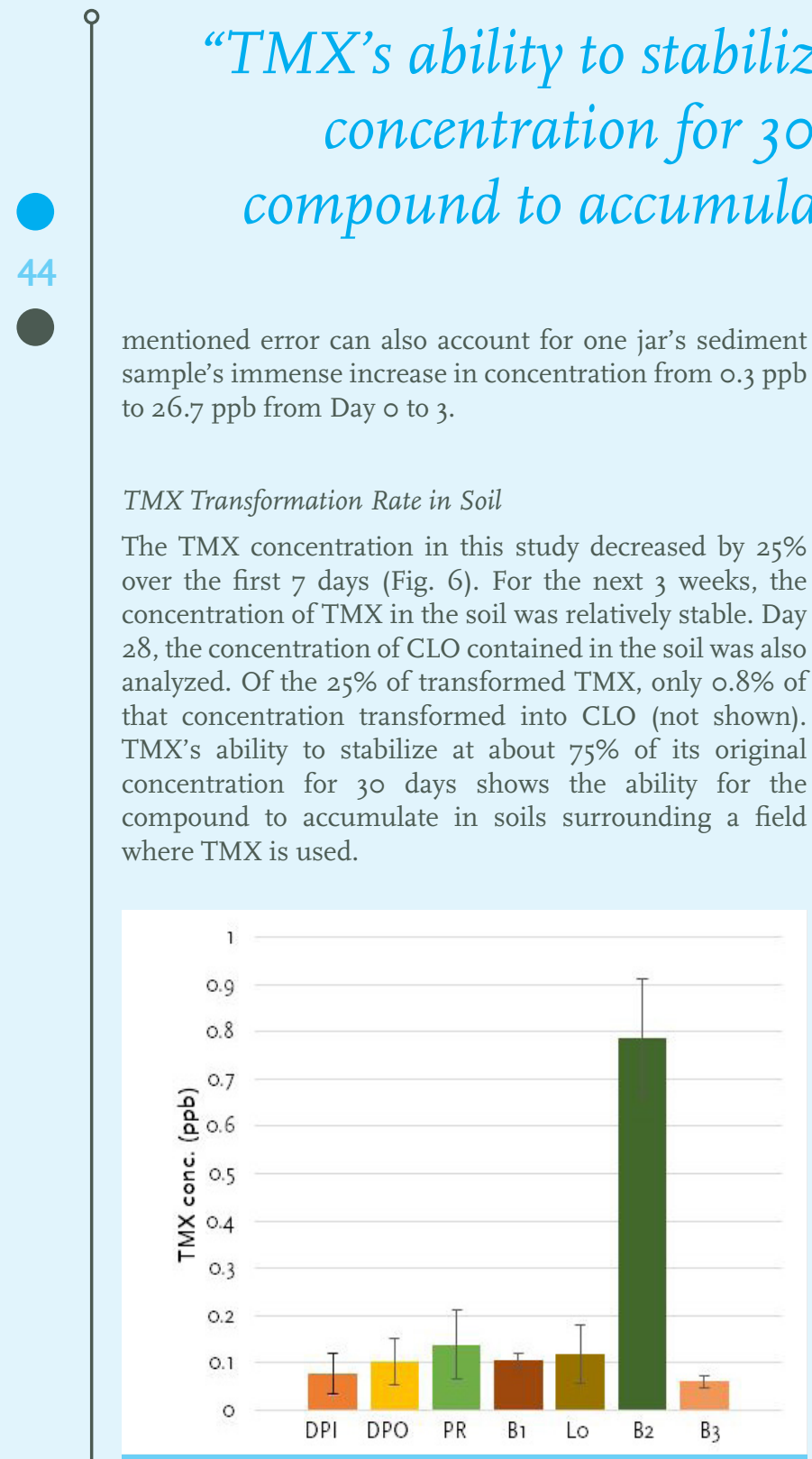

FIGURE 4. TMX CONCENTRATION (PPB) AT DESIGNATED LOCATIONS. THE LOCATIONS SHOWN HERE CORRELATE WITH THE LOCATIONS ON THE SAMPLE MAP (FIGURE 1). SEDIMENT AT LOCATIONS DPI AND B3 WERE BELOW DETECTION LIMIT, WHILE LOCATIONS DPO, PR, B1, AND LO WERE BETWEEN 0.1 PPB AND 0.16 PPB. SEDIMENT AT B2, ADJACENT TO THE CORNFIELD, WAS O.788 PPB.
CONCLUSIONS

The highest concentration of TMX was found in the sampling location adjacent to the cornfield, with at least five times the concentration of TMX compared to sediment concentration to other locations. Based on this data, it can be stated that TMX has the ability to mobilize from the cornfield to the creek. Since the concentration of TMX was below the detection limit at the next downstream location, it is assumed that TMX does not mobilize much through the creek itself. The transformation rates of TMX in sediment from Stroubles Creek were comparable to those found in previous aerobic water studies, ${ }^{14}$ while the transformation rate of CLO, which has limited literature, was similar to that of TMX. The transformation rate of TMX in soil was also comparable to that of previous studies, ${ }^{15}$ as the half-life of TMX in soil was at least double that of TMX in sediment. The lack of high concentration of CLO found on Day 28 soil samples was unexpected and this possibly contradicts a previous study, which had stated CLO as a main transformation product of TMX. ${ }^{\mathrm{I}}$ The analysis for CLO in the soil transformation study was not performed on previous study days for comparison. Therefore, the low concentration could be due to other reasons such as CLO degradation. The analysis of CLO concentrations in comparison to decreasing TMX concentrations is a possible topic for further study. Overall, the stability of TMX in soil suggests the ease with which the compound can accumulate to levels that would be dangerous to honey bees and other anthropods.

\section{ACKNOWLEDGEMENTS}

I acknowledge the support of the National Science Foundation through NSF/REU Site Grant EEC-I35905I. Any opinions, findings, and conclusions or recommendations expressed in this paper are those of the author(s) and do not necessarily reflect the views of the National Science Foundation.

I thank Dr. Kang Xia and Hanh Le for their continuous help and support throughout my research. 

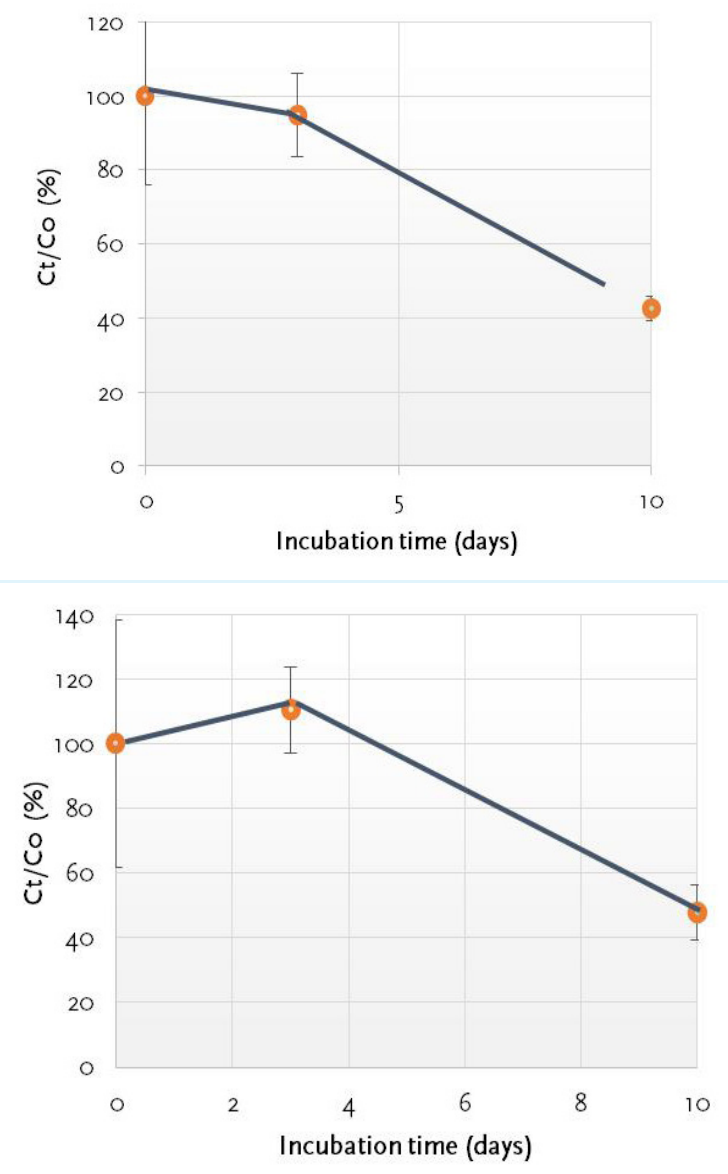

FIGURES 5A AND 5B. GRAPH SHOWING THE TRANSFORMATION RATE OF TMX (TOP) AND CLO (BOTTOM) IN SEDIMENT COLLECTED FROM STROUBLES CREEK. THE HALF-LIFE OF TMX IN THIS SEDIMENT WAS FOUND TO BE ABOUT 8 DAYS. THE HALF-LIFE OF CLO IN THIS SEDIMENT WAS FOUND TO BE ABOUT 9 DAYS.

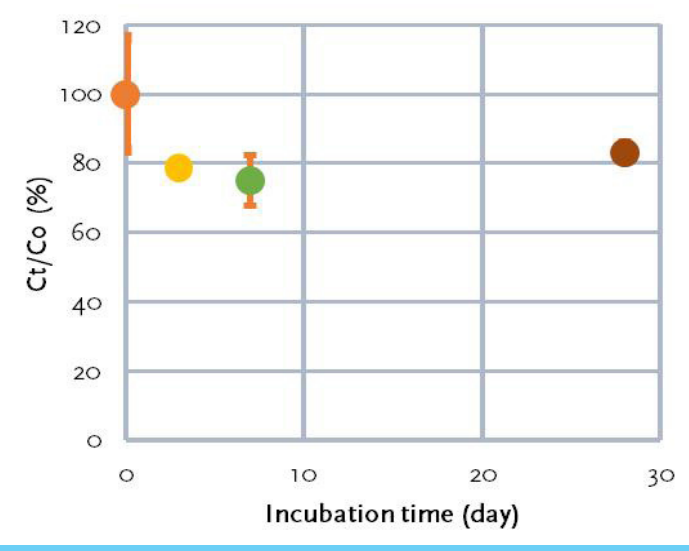

FIGURE 6. GRAPH SHOWING THE TRANSFORMATION OF TMX IN SOIL COLLECTED FROM THE VT AG. EXP. STATION. THE CONCENTRATION OF TMX IN THE SOIL DECREASED $25 \%$ OVER THE FIRST 7 DAYS OF INCUBATION.

\section{ENDNOTES}

I. Syngenta, "Thiamethoxam", 2005.

2. Murray, "Neonicotinoid Pesticides: Not Just a Bee Problem", 2015 .

3. Samson-Robert, et al., "Neonicotinoid-Contaminated Puddles of Water", 20I4.

4. European Food Safety Authority, "Conclusion on the risk of assessment for bees", 2013.

5. Sanchez-Bayo, "The Trouble with Neonicotinoids", 2014.

6. Main et al., "Widespread Use and Frequent Detection", 20I4. 7. Maienfisch et al., "Chemistry and Biology of Thiamethoxam", 2001 .

8. Hladik et al., "Widespread Occurrence of Neonicotinoid Insecticides", 2014.

9. EPA, "Clothianidin", 2003

IO. Schaafsma et al., "Neonicotinoid Insecticide Residues", 2015. II. Huseth \& Groves, "Environmental Fate of Soil Applied", 20I4. I2. Nauen et al., "Thiamethoxam is a Neonicotinoid Precursor", 2003 .

I3. Kwon et al., "Transformation of Triclosan and Triclocarbon", 2014 .

I4. Hladik et al., "Widespread Occurrence of Neonicotinoid Insecticides", 2014.

I5. Maienfisch et al., "Chemistry and Biology of Thiamethoxam", 200I.

I6. Nauen et al., "Thiamethoxam is a Neonicotinoid Precursor", 2003 


\section{REFERENCES}

EPA. Clothianidin. (2003).

European Food Safety Authority. "Conclusion on the risk assessment for bees for the active substance clothianidin." EFSA Journal, no. II(I) (2013): 3066.

Hladik, M. L., Kolpin, D. W., and Kuivila, K. M. "Widespread occurrence of neonicotinoid insecticides in streams in a high corn and soybean producing region, USA." Environmental Pollution, no. I93 (20I4): I89-I96, doi: го.IoI6/j. envpol.2014.06.033.

Huseth, A. S. and Groves, R. L. "Environmental Fate of Soil Applied Neonicotinoid Insecticides in an Irrigated Potato Agroecosystem." PLoS ONE, no. 9(5) e9708I (20I4), doi: 10.137I/journal.pone.009708I.

Kwon, J.-W., Armbrust, K. L., and Xia, K. “Transformation of Triclosan and Triclocarban in Soils and Biosolids-applied Soils." Journal of Environmental Quality, no. 39(4) (20I4): II39-II44, doi: I0.2I34/jeq2009.0055.

Maienfisch, P., Angst, M., Brandl, F., Fischer, W., Hofer, D., Kayser, H., . . . Widmer, H. "Chemistry and biology of thiamethoxam: a second generation neonicotinoid." Pest Management Science, no. 57(Iо) (200I): 906-9I3. doi: I0.1002/ps.365.

Main, A. R., Headley, J. V., Peru, K. M., Michel, N. L., Cessna, A. J., and Morrissey, C. A. "Widespread Use and Frequent Detection of Neonicotinoid Insecticides in Wetlands of Canada's Prairie Pothole Region." PLoS ONE, no. 9(3) e9282I (2014), doi: I0.I37I/journal.pone.009282I.

Murray, J. "Neonicotinoid Pesticides: Not Just a Bee Problem.” (C. o. S. Barbara, Trans.): City of Santa Barbara, Creeks Division (20I5).

Nauen, R., Ebbinghaus-Kintscher, U., Salgado, V. L., and Kaussmann, M. "Thiamethoxam is a neonicotinoid precursor converted to clothianidin in insects and plants." Pesticide Biochemistry and Physiology, no. 76(2) (2003): 5569. doi:Io.IoI6/So048-3575(03)00065-8.

Samson-Robert, O., Labrie, G., Chagnon, M., and Fournier, V. "Neonicotinoid-Contaminated Puddles of Water Represent a Risk of Intoxication for Honey Bees." PLoS ONE, no. 9(I2) eI08443 (20I4), doi: IO.I37I/journal. pone.oro8443.

Sánchez-Bayo, F. "The trouble with neonicotinoids." Science,no. 346(62II) (20I4):806-807. doi: IO.II26/science.1259159.

Schaafsma, A., Limay-Rios, V., Baute, T., Smith, J., and Xue, Y. "Neonicotinoid Insecticide Residues in Surface Water and Soil Associated with Commercial Maize (Corn) Fields in Southwestern Ontario." PLoS ONE, no. Io(2), eoII8I39. (2015), doi: I0.I37I/journal.pone.oII8I39.

Syngenta. Thiamethoxam. (2005) Retrieved from: http:// www.syngentacropprotection.com/env_stewardship/futuretopics/thiomethoxamenvirofacts_7-I9-05.pdf. 